\title{
Medical innovations and discoveries: the mind of a scientist is the most important research instrument
}

Sher L. Medical innovations and discoveries: the mind of a scientist is the most important research instrument. Acta Neuropyschiatrica 2003: 15:103-104. (C) Blackwell Munksgaard 2003

\author{
Leo Sher \\ Division of Neuroscience, Department of Psychiatry, Columbia \\ University, New York, NY, USA \\ Correspondence: Leo Sher, MD, Division of Neuroscience, \\ Department of Psychiatry, Columbia University, 1051 Riverside \\ Drive, Suite 2917, Box 42, New York, NY 10032, USA. \\ Tel. 212-543-6240; Fax: 212-543-6017; E-mail: Is2003@columbia.edu
}

Man has always tried to study the intricate workings of his own body and causes of illnesses. The human body has been slow to give up its secrets. The medical research road has been a long and difficult one with many problems to be overcome. The mind of a scientist has always been the principal research instrument.

Aristotle studied the properties of the propagation of genetic information in plants and animals (1). The fact that 'resemblance recurs at an interval of many generations' is Aristotle's important observation in this regard, suggesting that certain characteristics do not have to be expressed to the next generation to be perpetuated. Aristotle predicted the discovery of DNA: 'If again something creates this composition later', he wrote, 'it would be the cause of the resemblance.' Aristotle did not have a spectrophotometer and did not know about polymerase chain reaction.

The story of James Lind, a creative and astute clinician, is an interesting and thought-stimulating example. In 1747, the young physician from Scotland, conducted a study on the prevention and treatment of scurvy $(2,3)$. He chose 12 sailors with scurvy and divided them into six groups of two patients each. All 12 sailors received an identical diet but the six groups differed from one another in what they received as a supplement to the standard diet: cider, elixir of vitriol, vinegar; sea water, oranges and lemons, and a folk remedy which consisted of garlic, mustard seeds, horseradish, balsam of Peru, and gum myrrh. After 1 week of treatment patients who were given oranges and lemons improved dramatically.
None of other groups improved. Lind concluded that citrus fruit could treat or prevent scurvy. Lind made a discovery that saved many lives. However, it would be extremely difficult for Lind to publish his report nowadays. The number of cases involved in his experiment is very small in view of the way we conduct experimental studies today. He made a discovery on the basis of statistically non-significant data.

Edward Jenner, a country practitioner in England, heard stories from farmers and dairy maids that anyone who had been infected with cowpox, a relatively mild disease that could be contracted from cattle, could not become infected with smallpox $(4,5)$. Unlike colleagues whose responses were laughter and disbelief, Jenner gave these tales serious thought. He understood that cowpox not only protected against smallpox but could be transmitted from one person to another as a 'deliberate mechanism of protection'. In 1796, Jenner performed the historic first vaccination. He made the first step in the long process whereby smallpox, a disease that for many centuries devastated mankind, would be eradicated.

In the 1840s puerperal, or childbed, fever, infection after childbirth, was taking the lives of up to $30 \%$ of the women giving birth in hospitals, whereas most women who gave birth at home remained relatively unaffected. Ignaz Phillipp Semmelweis, a Hungarian physician, noticed that women who were examined by student doctors who had not washed their hands after leaving the autopsy room had much higher mortality rates $(6,7)$. Semmelweis understood that the puerperal 
fever was septic and contagious. By ordering students to wash their hands with chlorinated lime before examining patients, Semmelweis dramatically reduced the maternal mortality. He introduced antisepsis into medical practice. It was one of the most important events in the history of medicine.

A considerable number of medical discoveries have been made throughout the human history. How did this good fortune arise? Clearly, discoveries were solely due to the uniqueness and genius of the researchers involved.

Modern research instruments and statistical analysis are very important for the development of medical sciences. The progressive development of increasingly sophisticated and precise medical research techniques provides new opportunities to unravel the mysteries of the human body. However, neither powerful research instruments nor contemporary statistical analysis can replace the sharpness of mind of a clinical researcher. Careful observation of everyday occurrences can reveal phenomena of immense utility, obscured by their sheer familiarity. A creative person is able to extract and synthesize information encapsulated in sensory stimulation and has a propensity to explore anomalous alternatives, remain flexible, original and seek out elaboration (8). As Schopenhauer noted, the task of the creative mind is 'not so much to see what no one has seen yet; but to think what nobody has thought yet, about what everyone sees' (9).

\section{References}

1. Diamandopoulos AA, Goudas PC. Cloning's not a new idea: the Greeks had a word for it centuries ago. Nature 2000;408:905.

2. Editorial. James Lind (1716-1794). Ind J Physiol Pharmacol 1994;38:151-152.

3. Wynder EL. A corner of history. James Lind's discovery of the causes of scurvy. Prev Med 1974;3:300-305.

4. Bloch H. Edward Jenner (1749-1823). The history and effects of smallpox, inoculation, and vaccination. Am J Dis Child 1993;147:772-774.

5. Willis NJ. Edward Jenner and the eradication of smallpox. Scot Med J 1997;42:118-121.

6. Wyllicky H, Skopec M. Ignaz Philipp Semmelweis, the prophet of bacteriology. Infect Control 1983;4:367-370.

7. Newsom SW. Pioneers in infection control. Ignaz Philipp Semmelweis. J Hosp Infect 1993;23:175-187.

8. Von Bertalanffy L. Problems of Life. New York: Harper Torchbooks, 1960: 1.

9. GuILFORD JP. The relation of intellectual factors to creative thinking in science. In: TAYLOR CW, ed. The 1955 University of Utah Research Conference on the Identification of Creative Scientific Talent. Salt Lake City: University of Utah Press 1956: 69-95. 